\title{
Heterogeneity of the Frequency Domain Patterns in Persistent Atrial
}

\section{Fibrillation}

Shahriar Iravanian, MD, and Jonathan J Langberg, MD

\section{Emory University}

\section{Contact Information:}

15 Jonathan J. Langberg, M.D.

Professor of Medicine

Emory University Hospital

1364 Clifton Road, NE, Ste D403C

Atlanta, GA 30322

20 email: jlangbe@emory.edu

Subject Terms: Atrial Fibrillation, Catheter ablation, Computational Biology 


\section{Iravanian, Langberg. Frequency Domain Patterns in Atrial Fibrillation.}

\section{Abstract \\ 25 Background:}

Persistent atrial fibrillation (AF) has remained a challenging clinical problem. The mechanisms of persistent AF are still subject to debate. Both a single mother-rotor with fibrillatory conduction and multiple meandering spiral waves have been proposed to explain persistent AF. Previous frequency domain studies have reported the presence of dominant frequency (DF) gradient (a marker of single

30 mother-rotor) in paroxysmal, but not persistent AF.

\section{Methods and Results:}

We performed temporally-dense high-resolution frequency domain analysis of 10-40 minutes segments of intracardiac signals recorded in 24 patients undergoing ablation of persistent AF. We observed two predominant patterns. The expected signature of the mother-rotor mechanism was observed in $38 \%$ of

35 the patients. The frequency pattern in 54\% consisted of two or more distinct frequency peaks with no obvious gradient, which is consistent with multiple separate primary spiral waves in electrophysiologically heterogeneous areas of atria. The average measured number of rotors per case was $1.71 \pm 0.32$, which provides a lower limit on the actual number of rotors. The single-zone pattern was exclusively seen in patients who were on a membrane-active antiarrhythmic medication at the time

40 of ablation $(\mathrm{P}<0.005)$.

\section{Conclusions:}

AF is a heterogeneous disorder. High-frequency resolution analysis is a useful tool to detect the underlying mechanisms of AF and to classify it into patterns consistent with a single mother-rotor vs. multiple meandering wavelets.

Key words: atrial fibrillation, ablation, dominant frequency, rotors 


\section{Iravanian, Langberg. Frequency Domain Patterns in Atrial Fibrillation.}

\section{Introduction}

Atrial fibrillation (AF) is the most common clinical arrhythmia and is responsible for significant morbidity and mortality. AF management has remained a challenging problem. Antiarrhythmic

50 medications and ablation procedures are commonly used to control AF, ${ }^{1}$ but neither intervention is very effective, especially when AF progresses to the persistent stage.

Paroxysmal AF is commonly initiated by triggers from pulmonary veins. ${ }^{2}$ However, as AF progresses gradually to the persistent phase, the role of pulmonary veins diminishes and AF is sustained as a result

55 of spiral waves and spatiotemporal chaos. The exact spatiotemporal organization of the spiral waves (rotors) and their response to various interventions (in the form of medications, ablation, or pacing) are not fully characterized and are still subject to intense debate. ${ }^{3}$ In particular, it is not clear whether AF is caused by a single anchored mother rotor with fibrillatory conduction to the rest of atria or whether it is the result of multiple interacting spiral waves with no obvious hierarchy (i.e., each spiral wave is as

60 primary as the others). Settling this question has important ramifications in the management of AF. However, the complexity of AF has precluded an easy answer.

The pioneering works of Moe and later Allessie et al. let to the concept of multi-wavelet reentry as the mechanism of AF. ${ }^{4-6}$ Experimental work by Jalife and colleagues in late 1990s demonstrated the

65 presence of a gradient in dominant frequency (DF) of intracardiac signals during AF, suggesting an alternative explanation of a single "mother" rotor, usually anchored in the posterior left atrium, with fibrillatory conduction to the rest of the atria. ${ }^{7-9}$ This hypothesis is supported (at least in some experimental models) by the direct visualization of stable spiral waves using optical 


\section{Iravanian, Langberg. Frequency Domain Patterns in Atrial Fibrillation.}

mapping. ${ }^{10}$ Applying frequency-domain analysis to clinical AF in humans, Lazar et al. detected a DF

70 gradient in paroxysmal but not persistent AF. ${ }^{11}$

Previously, we analyzed the intracardiac recordings during ablation of persistent AF using both time and frequency domain analysis methods to gain mechanistic insight into AF. ${ }^{12,13}$ We showed that temporally-dense and high-resolution frequency domain analysis is a valuable tool in elucidating the

75 spatiotemporal dynamics of AF. Our main finding was that transitions from irregular and chaotic AF to regular flutter occur suddenly and have the hallmarks of phase transitions in complex dynamical systems. $^{14}$

In this study, we expand on our previous work by focusing our attention on the dynamics and number

80 of rotors during persistent AF. We postulate that it is possible to differentiate between the two putative mechanisms of AF by looking for their expected frequency domain signatures. In the case of a single rotor, we expect to see an area of fast and regular activity (a narrow peak in the frequency domain) with fibrillatory conduction to the rest of atria. This is the classic DF gradient pattern seen in previous studies. On the other hand, the predicted pattern for multiple independent rotors is different than DF

85 gradient and is marked by multiple spatially-localized frequency peaks.

\section{Methods}

\section{Patient Population and Ablation Procedure}

The procedural and data collection methods were previously described. ${ }^{12}$ The study protocol was

90 approved by the Emory University Institutional Review Board. The data were collected retrospectively from catheter ablation procedures for persistent AF done at the Emory University Hospital, Atlanta, 
Iravanian, Langberg. Frequency Domain Patterns in Atrial Fibrillation.

GA. The procedure included radiofrequency-based isolation of pulmonary veins and substrate modification by targeting complex fractionated atrial electrograms (CFAE). ${ }^{15}$

95 All patients were in persistent AF at the time of ablation. A duodecapolar catheter (Livewire, St Jude Medical) was placed in the right atrium and advanced into the coronary sinus, such that on average, the distal five electrode pairs were in the coronary sinus and recording from the left atrium. Bipolar intracardiac signals from the duodecapolar catheter were recorded continuously for the duration of the procedure using a Cardio Lab System (GE Medical). The signals were band-passed filtered at 30-500

$100 \mathrm{~Hz}$, digitalized at 12 bits of resolution, sampled at $977 \mathrm{~Hz}$, and were downloaded for offline processing.

\section{Signal Processing}

Each channel was divided into 16384-point segments ( 16 seconds) with 50\% overlap between them. The segments were detrended, rectified and transformed into the frequency domain with a resolution of

105 1/16 Hz. The resulting power spectra were normalized to the peak value at each segment. Short-Time Fourier Transform (STFT) graphs and the combined power spectrum of selected regions were used to describe the dynamics and were correlated with the raw intracardiac electrograms.

\section{Results}

110 Episodes of AF in 24 patients undergoing ablation of persistent AF were classified into three groups based on the frequency domain analysis of a 10-40 min segment of uninterrupted AF:

1. Single Zone: in this group, there was a continuous frequency gradient from a fast area to the rest of the channels. The main signature of this type as seen in the power spectrum is a narrow 
Iravanian, Langberg. Frequency Domain Patterns in Atrial Fibrillation.

and fast frequency peak with gradual slowing and widening in more distant channels (Figure 1A).

2. Dual- or Multi-Zone: in this group, there were two or more distinct frequency zones with no apparent gradient. In some cases, there were overlaps between the zones, such that a single channel straddled more than one zone and exhibited two or more peaks in the power spectrum (Figure 1B). It should be noted that if we had used a shorter Fourier Transformation window (e.g., a 2 to 4-second window instead of the 16-second one), the resulting lower resolution would have smeared and obscured the dual peaks and the resulting pattern could have been misidentified as a single zone (Figure 1C).

3. Complex Pattern: this is a mixture of the two previous types with multiple distinct zones with areas of frequency gradient.

The mean age of the patients was 61 years old (95\% confidence interval [CI] 45-77 years). Fifteen patients were male (63\%).

130 We observed the single zone type in 9 out of the 24 cases (38\%). The multi-zone signature was seen in 13 cases (54\%, 11 with two zones and 2 with three or more). The frequency patterns were too complex to distinguish between the single or multi-zones in two cases and were therefore designated as complex. The average number of detected rotors per case was 1.71 (CI 1.39-2.03). This is a lower bound on the actual number of rotors as the duodecapolar catheter samples only a portion of the atria.

Fourteen patients were taking a class I and class III antiarrhythmic medication at the time of ablation, 9 exhibited a dual/multi-zone pattern, and 5 displayed a single-zone pattern. On the other hand, all the 


\section{Iravanian, Langberg. Frequency Domain Patterns in Atrial Fibrillation.}

patients who were not on an antiarrhythmic medication had a dual/multi-zone pattern $(\mathrm{P}<0.005$,

Fisher's exact test).

Figure 2 displays a clear cut example of a single zone with frequency gradient. In this case, the right atrium is in a stable flutter, but the left atrium is in AF. There is a single narrow peak on the right atrial channels in the power spectra (panel C) with a gradual slowing and widening as we move toward the proximal coronary sinus. We interpret this pattern as a flutter in the right atrium with fibrillatory

145 conduction to the left atrium through the Bachmann's bundle.

Most cases of single zone type are not as dramatic as Figure 2. Figure 3 depicts a typical single zone case. Here, the peak frequency is in the lateral right atrium with a gradual slowing toward the proximal coronary sinus, as seen by the chevron pattern of the peaks in the spectrograms (similar to Figure 1A).

Figure 4 represents a typical dual zone AF. There are two distinct and widely separated frequency peaks: a fast one at $6.0 \mathrm{~Hz}$, which is mainly seen in the left atrial channels, and a slower predominantly right-atrial peak at $4.5 \mathrm{~Hz}$. These peaks remain well separated with no gradual transition from one to the other. The intracardiac signals (panel B) from the two zones show regular activity with different 155 cycle lengths. This pattern is in contrast to Figure 3B, where there is a fractioned signal on the slower side. Another dual zone example is presented in Figure 5. Again, there are two distinct peaks. However, their separation is less $(5.3$ and $6.3 \mathrm{~Hz}$ ), and the two peaks are partially fused in the middle channels (similar to Figure 1C). 


\section{Iravanian, Langberg. Frequency Domain Patterns in Atrial Fibrillation.}

160 Some cases exhibit more than two peaks. Figure 6 is an example of at least three distinct frequency peaks. The slowest peak (seen mainly in channel RA5) is very narrow, suggestive of regular activity. Interestingly, there is also a hint of a fourth peak in channel LA5, which is fast and narrow.

\section{Pattern Stability}

165 In this study, the frequency patterns were assigned based on the data recorded while ablation lesions were applied. To show the stability of patterns during AF, we divided the period of AF from the beginning of the ablation to the time of the first transition to a flutter or sinus rhythm into two halves and compared the peaks in the frequency domain. Figure 7 shows four representative examples. In some cases, the frequency peaks shifted slightly toward lower frequencies as a result of ablation, but

170 the relative structure of the peaks and the designation to a single or multi-zone pattern remained the same.

\section{Transitions from AF to Flutter}

Previously, we have described sudden transitions from AF to a regular flutter. ${ }^{12,13}$ A detailed analysis of

175 these transitions is useful in revealing the underlying dynamics. Figure 8A shows such a transition in a multi-zone AF. In this case, ablation per se did not organize the rhythm to a flutter, and ibutilide was infused near the end of the case to promote the transition. Before the ablation, two distinct peaks were seen throughout the case. After ibutilide infusion, both peaks slowed down and then flutter emerges from the lower frequency peak, as if the eventual flutter was present, but constrained to one region,

180 during persistent AF. This finding argues that the slower peak is also a primary reentrant source and not merely a manifestation of conduction block from a faster source. 


\section{Iravanian, Langberg. Frequency Domain Patterns in Atrial Fibrillation.}

A similar pattern is present in Figure 8. Panels B and C, corresponding to different channels of a dual zone case, follow the slower and faster peaks, respectively. Ablation-induced flutter emerges from the 185 slower peak.

\section{Discussion}

AF is a heterogeneous disease. The mechanisms of AF may vary in different patients and can evolve and changes over time in the same individual as a result of electrical and structural remodeling. ${ }^{16}$ This

190 heterogeneity of mechanism manifests as variable frequency domain patterns of intracardiac signals. However, in this study, we show that the frequency spectra during persistent AF are stable and can be broadly classified into two major groups: single-zone and multi-zone patterns.

We detected the frequency domain signature of a single rotor in less than $40 \%$ of the cases. The majority of the rest are classified as dual or multi-zone patterns, which we interpret as the evidence of multiple distinct driver domains in electrophysiologically heterogeneous regions of atria, ${ }^{17}$ and not necessarily multiple coexisting anchored and localized spiral waves. Therefore, both the mother rotor and multiple wavelet hypotheses may be applicable in certain subgroups of patients with persistent AF.

200 The recognition of single vs. multi-zone pattern in a given patient may have therapeutic implications. For example, Focal Impulse and Rotor Modulation (FIRM) technique was initially developed assuming a single mother rotor as the underlying mechanism of AF. ${ }^{18}$ However, clinical studies did not corroborate this assumption. Later clinical studies using FIRM reported an average $2.8 \pm 1.4$ source per patient. ${ }^{19}$ Based on our results, it is possible that the group of patients who have in fact a single rotor 205 are better suited for FIRM ablation. 
Membrane-active antiarrhythmic medications (class I and III) had a significant effect on the frequency pattern of AF. Specially, we observed no single-zone pattern in patients who were not taking an antiarrhythmic. These medications, by reducing the excitability (for sodium-channel blockers) or

210 prolonging the action potential duration (for the potassium-channel blockers), increase the reentry cycle length and decrease the potential number of rotors that can be fit onto atria. This result may explain the failure to detect DF gradient in persistent AF in previous studies, ${ }^{11}$ and argues for performing rotor mapping without interruption of antiarrhythmic medications at the time of the procedure.

215 Temporally-dense frequency domain analysis is a useful tool that can be used to classify AF before interventions such as ablation. As is evident from visual inspection of the unprocessed signals in Figures 2 to 6 , it is not possible to discern the patterns which are readily apparent in the frequency domain. Moreover, this kind of analysis can be helpful in characterizing and localizing rotors, especially if applied to multi-channel basket catheters covering a larger area of atria. For example, in

220 the single-zone with gradient pattern, the anchored spiral wave is likely to be closer to the channel with a fast and narrow frequency peak, whereas this statement is not necessarily true for the multi-zone pattern. Also, it is plausible that the underlying pattern is correlated with the immediate and long-term results of ablation.

225 From a practical standpoint, the ability to resolve frequency peaks requires a minimum frequency resolution of $\sim 0.1 \mathrm{~Hz}(0.067 \mathrm{~Hz}$ in our study). Many dominant frequency (DF) studies in AF employ a window too short for robust detection of the different patterns. 


\section{Iravanian, Langberg. Frequency Domain Patterns in Atrial Fibrillation.}

\section{Limitations}

230 Our data was collected during ablation of persistent AF. The ongoing ablation affects the frequency content of the signals. However, the pattern remained stable during ablation.

The relatively small sample size of the study precludes the assessment of the association between the frequency patterns and the success of ablation.

The interpretation of the different patterns as signifying a single or multiple rotors is indirect, as the recording was done by a duodecapolar catheter placed in the right atrium and coronary sinus. This provides only a limited and far from the action view of the atria (spiral waves preferentially localize to the posterior left atrium and areas around the pulmonary veins). Also, we expect that such a limited

240 view underestimates the actual number of rotors.

\section{Disclosures}

The authors have no conflict of interest to declare. 


\section{Iravanian, Langberg. Frequency Domain Patterns in Atrial Fibrillation.}

\section{References}

1. Calkins H, Hindricks G, Cappato R, Kim Y-H, Saad EB, Aguinaga L, Akar JG, Badhwar V, Brugada J, Camm J, Chen P-S, Chen S-A, Chung MK, Nielsen JC, Curtis AB, Davies DW, Day JD, d'Avila A, de Groot NMS (Natasja), Di Biase L, Duytschaever M, Edgerton JR, Ellenbogen KA, Ellinor PT, Ernst S, Fenelon G, Gerstenfeld EP, Haines DE, Haissaguerre M, Helm RH, Hylek E, Jackman WM, Jalife J, Kalman JM, Kautzner J, Kottkamp H, Kuck KH, Kumagai K, Lee R, Lewalter T, Lindsay BD, Macle L, Mansour M, Marchlinski FE, Michaud GF, Nakagawa H, Natale A, Nattel S, Okumura K, Packer D, Pokushalov E, Reynolds MR, Sanders P, Scanavacca M, Schilling R, Tondo C, Tsao H-M, Verma A, Wilber DJ, Yamane T. 2017 HRS/EHRA/ECAS/APHRS/SOLAECE expert consensus statement on catheter and surgical ablation of atrial fibrillation. Hear Rhythm [Internet]. 2017 [cited 2018 Mar 3];14:e275-e444. Available from: http://www.ncbi.nlm.nih.gov/pubmed/28506916

2. Haïssaguerre M, Jaïs P, Shah DC, Takahashi A, Hocini M, Quiniou G, Garrigue S, Le Mouroux A, Le Métayer P, Clémenty J. Spontaneous initiation of atrial fibrillation by ectopic beats originating in the pulmonary veins. N Engl J Med [Internet]. 1998 [cited 2013 Oct 25];339:65966. Available from: http://www.ncbi.nlm.nih.gov/pubmed/9725923

3. Waks JW, Josephson ME. Mechanisms of Atrial Fibrillation - Reentry, Rotors and Reality. Arrhythmia Electrophysiol Rev [Internet]. 2014 [cited 2018 Mar 3];3:90-100. Available from: http://www.ncbi.nlm.nih.gov/pubmed/26835073

4. Moe GK. A conceptual model of atrial fibrillation. J Electrocardiol [Internet]. 1968 [cited 2013 Oct 25];1:145-6. Available from: http://www.ncbi.nlm.nih.gov/pubmed/5707064

5. Allessie MA, Bonke FI, Schopman FJ. Circus movement in rabbit atrial muscle as a mechanism of tachycardia. III. The \&quot;leading circle\&quot; concept: a new model of circus movement in cardiac tissue without the involvement of an anatomical obstacle. Circ Res [Internet]. 1977 [cited 2018 Mar 3];41:9-18. Available from: http://www.ncbi.nlm.nih.gov/pubmed/862147

270 6. Allessie, Lammers W, Bonke F, Hollen J. Experimental evaluation of Moe's multiple wavelet hypothesis of atrial fibrillation. 1985;

7. Mandapati R, Skanes A, Chen J, Berenfeld O, Jalife J. Stable Microreentrant Sources as a Mechanism of Atrial Fibrillation in the Isolated Sheep Heart. Circulation [Internet]. 2000 [cited 2013 Jun 1];101:194-199. Available from: http://circ.ahajournals.org/content/101/2/194.long

275 8. Mansour M, Mandapati R, Berenfeld O, Chen J, Samie FH, Jalife J. Left-to-right gradient of atrial frequencies during acute atrial fibrillation in the isolated sheep heart. Circulation [Internet]. 2001 [cited 2018 Mar 3];103:2631-6. Available from: http://www.ncbi.nlm.nih.gov/pubmed/11382735 


\section{Iravanian, Langberg. Frequency Domain Patterns in Atrial Fibrillation.}

9. Jalife J, Berenfeld O, Mansour M. Mother rotors and fibrillatory conduction: a mechanism of atrial fibrillation. Cardiovasc Res [Internet]. 2002 [cited 2013 May 13];54:204-16. Available from: http://www.ncbi.nlm.nih.gov/pubmed/12062327

10. Filgueiras-Rama D, Martins RP, Ennis SR, Mironov S, Jiang J, Yamazaki M, Kalifa J, Jalife J, Berenfeld O. High-resolution endocardial and epicardial optical mapping in a sheep model of stretch-induced atrial fibrillation. J Vis Exp [Internet]. 2011 [cited 2018 Mar 7];Available from: http://www.ncbi.nlm.nih.gov/pubmed/21841762

11. Lazar S, Dixit S, Marchlinski FE, Callans DJ, Gerstenfeld EP. Presence of Left-to-Right Atrial Frequency Gradient in Paroxysmal but Not Persistent Atrial Fibrillation in Humans. Circulation [Internet]. 2004 [cited 2018 Mar 3];110:3181-3186. Available from:

http://www.ncbi.nlm.nih.gov/pubmed/15533867

290 12. Iravanian S, Lloyd MS, Langberg JJ. Left atrial flutter accelerates during ablation of atrial fibrillation: a paradoxical effect of electrical remodelling. Europace [Internet]. 2012 [cited 2013 Apr 7];14:761-6. Available from: http://www.ncbi.nlm.nih.gov/pubmed/22183745

13. Iravanian S, Langberg JJ. Spatiotemporal organization during ablation of persistent atrial fibrillation. Heart Rhythm [Internet]. 2015 [cited 2015 May 23];Available from: http://www.ncbi.nlm.nih.gov/pubmed/25916566

14. Iravanian S, Langberg JJ. Critical phase transitions during ablation of atrial fibrillation. Chaos An Interdiscip J Nonlinear Sci [Internet]. 2017 [cited 2017 Dec 2];27:93925. Available from: http://www.ncbi.nlm.nih.gov/pubmed/28964135

15. Hayward RM, Upadhyay GA, Mela T, Ellinor PT, Barrett CD, Heist EK, Verma A, Choudhry NK, Singh JP. Pulmonary vein isolation with complex fractionated atrial electrogram ablation for paroxysmal and nonparoxysmal atrial fibrillation: A meta-analysis. Heart Rhythm [Internet]. 2011 [cited 2013 Jun 13];8:994-1000. Available from: http://www.ncbi.nlm.nih.gov/pubmed/21397045

16. Nattel S, Burstein B, Dobrev D. Atrial remodeling and atrial fibrillation: mechanisms and implications. Circ Arrhythm Electrophysiol [Internet]. 2008 [cited 2018 Mar 4];1:62-73. Available from: http://www.ncbi.nlm.nih.gov/pubmed/19808395

17. Haissaguerre M, Hocini M, Denis A, Shah AJ, Komatsu Y, Yamashita S, Daly M, Amraoui S, Zellerhoff S, Picat M-Q, Quotb A, Jesel L, Lim H, Ploux S, Bordachar P, Attuel G, Meillet V, Ritter P, Derval N, Sacher F, Bernus O, Cochet H, Jais P, Dubois R. Driver Domains in Persistent Atrial FibrillationCLINICAL PERSPECTIVE. Circulation [Internet]. 2014 [cited 2017 May 15];130. Available from: http://circ.ahajournals.org/content/130/7/530.long 
bioRxiv preprint doi: https://doi org/10.1101/285031; this version posted March 19,2018. The copyright holder for this preprint (which was not

certified by peer review) is the author/funder, who has granted bioRxiv a license to display the preprint in perpetuity. It is made available under aCC-BY-NC 4.0 International license.

\section{Iravanian, Langberg. Frequency Domain Patterns in Atrial Fibrillation.}

18. Narayan SM, Krummen DE, Shivkumar K, Clopton P, Rappel W-J, Miller JM. Treatment of atrial fibrillation by the ablation of localized sources: CONFIRM (Conventional Ablation for Atrial Fibrillation With or Without Focal Impulse and Rotor Modulation) trial. J Am Coll Cardiol [Internet]. 2012 [cited 2014 Dec 4];60:628-36. Available from:

http://www.pubmedcentral.nih.gov/articlerender.fcgi?

artid=3416917\&tool=pmcentrez\&rendertype=abstract

19. SWARUP V, BAYKANER T, ROSTAMIAN A, DAUBERT JP, HUMMEL J, KRUMMEN DE, TRIKHA R, MILLER JM, TOMASSONI GF, NARAYAN SM. Stability of Rotors and Focal Sources

320 for Human Atrial Fibrillation: Focal Impulse and Rotor Mapping (FIRM) of AF Sources and Fibrillatory Conduction. J Cardiovasc Electrophysiol [Internet]. 2014 [cited 2017 May 15];25:n/a-n/a. Available from: http://www.ncbi.nlm.nih.gov/pubmed/25263408 


\section{Figure Legends}

1. Schematics of different frequency patterns. A shows a single-zone pattern with a narrow peak at the fastest frequency (RA1) and a frequency gradient and wider peaks toward the slower frequencies. The resulting pattern is "chevron-shaped”. B displays a dual-zone pattern. $\mathbf{C}$ is the same data as $\mathbf{B}$, but depicted at a lower frequency resolution. Fusion of the peaks, especially in the middle spectra, results in an apparent gradient and may be interpreted by mistake as a single-zone.

2. An extreme example of single-zone frequency pattern. A depicts the STFT spectra of a 15minute segment of intracardiac signals obtained from ten recording channels during AF. The right atrial (RA1-RA5) channels have a narrow spectral peak, consistent with flutter. The left atrial (LA1-LA5) channels show double peaks: the same narrow signal as the left (red arrow), and a wider and slower peak correlated with fibrillatory conduction (green arrow). B Two 5second segments of unprocessed intracardiac signals. The black horizontal bar is $500 \mathrm{~ms}$. C The averaged spectra. The spectra are shifted vertically for better visualization.

3. A typical example of single-zone frequency pattern. A depicts the STFT spectra of a 30minute segment of intracardiac signals obtained from ten recording channels during AF. The fastest channel with a narrow frequency peak is RA1 (red arrow). There is gradual widening and slowing of the peak toward LA1/RA5 region. B Two 5-second segments of unprocessed intracardiac signals. Note regular activity in RA1 and slower and fractioned atrial signals in LA2. The black horizontal bar is $500 \mathrm{~ms}$. C The averaged spectra. The spectra are shifted vertically for better visualization.

4. A typical example of dual-zone frequency pattern. A depicts the STFT spectra of a 10minute segment of intracardiac signals obtained from ten recording channels during AF. There 


\section{Iravanian, Langberg. Frequency Domain Patterns in Atrial Fibrillation.}

are two well-separated frequency peaks (red and green arrows). Channels LA1 to LA4 exhibit both peaks. B Two 5-second segments of unprocessed intracardiac signals. The black horizontal bar is 500 ms. C The averaged spectra. The spectra are shifted vertically for better visualization.

5. Another example of dual-zone frequency pattern. A depicts the STFT spectra of a 20-minute segment of intracardiac signals obtained from ten recording channels during AF. There are two frequency peaks (red and green arrows). The separation between the channels is less than Figure 4. Channels RA3 to RA5 exhibit fused frequency peaks. B Two 5-second segments of unprocessed intracardiac signals. Note fast and regular activity in LA5. The black horizontal bar is 500 ms. C The averaged spectra. The spectra are shifted vertically for better visualization.

6. An example of multi-zone frequency pattern. A depicts the STFT spectra of a 20-minute segment of intracardiac signals obtained from ten recording channels during AF. There are four frequency peaks (red, green, yellow and cyan arrows). Multiple channels show double peaks: red/yellow in LA4 and LA5, green/cyan in RA3 and RA5, and possibly red/green in RA1. B Two 5-second segments of unprocessed intracardiac signals. Note fast and irregular activity as a result of superimposition of multiple peaks. The black horizontal bar is $500 \mathrm{~ms}$. C The averaged spectra. The spectra are shifted vertically for better visualization.

7. Comparison of frequency patterns during AF ablation. AF episodes from the beginning of ablation to the time of the first termination were divided into two halves. Each panel displays the overlapped frequency peaks. The first half is drawn in blue and the second half in red. Note the near perfect match between the two halves. The main difference is that the second halves are slightly shifted toward lower frequencies, but the general pattern remains the same. $\mathbf{A}$ and $\mathbf{B}$ show a multi-zone pattern, and $\mathbf{C}$ and $\mathbf{D}$ a single-zone pattern. 
8. Examples of AF to flutter transitions. A shows the full STFT of channel RA5 from Figure 6.

Note the presence of two well-defined frequency peaks that can be followed from the beginning of the recording up to the transition at 167 min. The potassium-channel blocker ibutilide was infused at 160 min, resulting in the global slowing of atrial activities. $\mathbf{B}$ and $\mathbf{C}$ show partial STFT of channels LA4 and RA4 from Figure 5. Note that the frequency peak in $\mathbf{B}$ is lower. Also, the flutter emerges from the slower peak (B) rather than the faster peak in $\mathbf{C}$. 
bioRxiv preprint doi: https://doi.org/10.1101/285031; this version posted March 19,2018. The copyright holder for this preprint (which was not certified by peer review) is the author/funder, who has granted bioRxiv a license to display the preprint in perpetuity. It is made available under aCC-BY-NC 4.0 International license.

Iravanian, Langberg. Frequency Domain Patterns in Atrial Fibrillation.

\section{$375 \quad$ Figure 1}
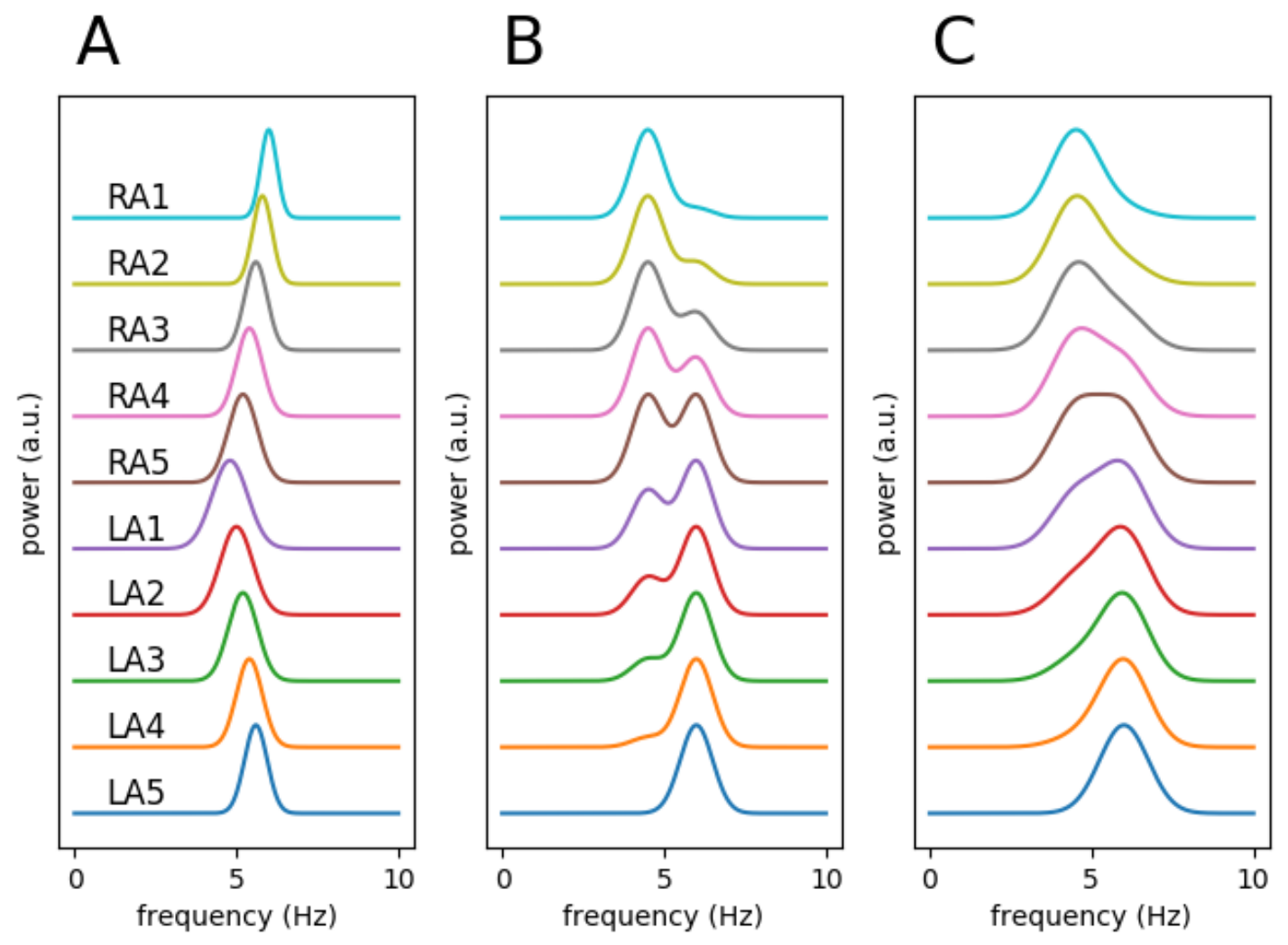
bioRxiv preprint doi: https://doi.org/10.1101/285031; this version posted March 19, 2018. The copyright holder for this preprint (which was not certified by peer review) is the author/funder, who has granted bioRxiv a license to display the preprint in perpetuity. It is made available under aCC-BY-NC 4.0 International license.

Iravanian, Langberg. Frequency Domain Patterns in Atrial Fibrillation.

Figure 2

A
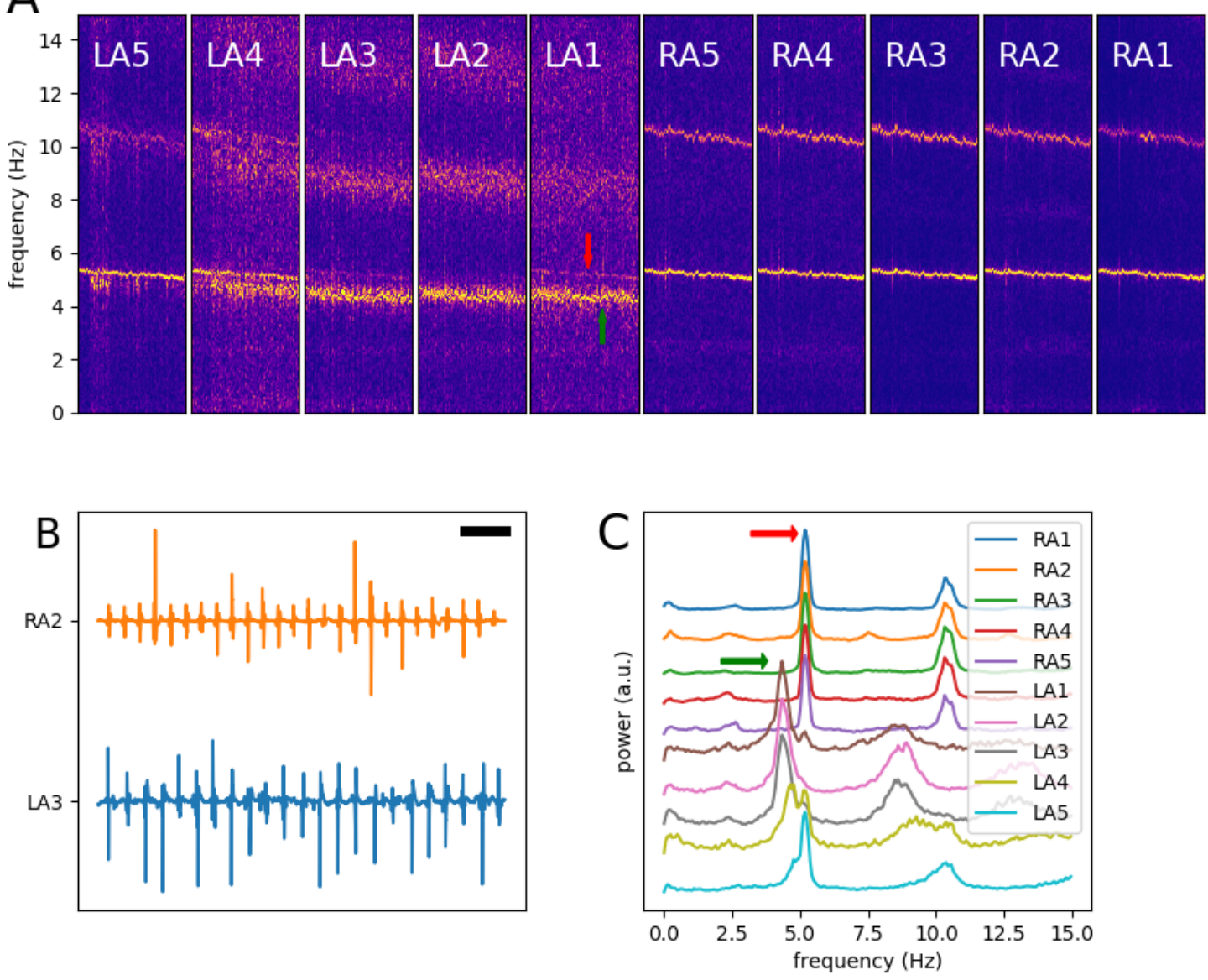
bioRxiv preprint doi: https://doi.org/10.1101/285031; this version posted March 19,2018 . The copyright holder for this preprint (which was not certified by peer review) is the author/funder, who has granted bioRxiv a license to display the preprint in perpetuity. It is made available under aCC-BY-NC 4.0 International license.

Figure 3
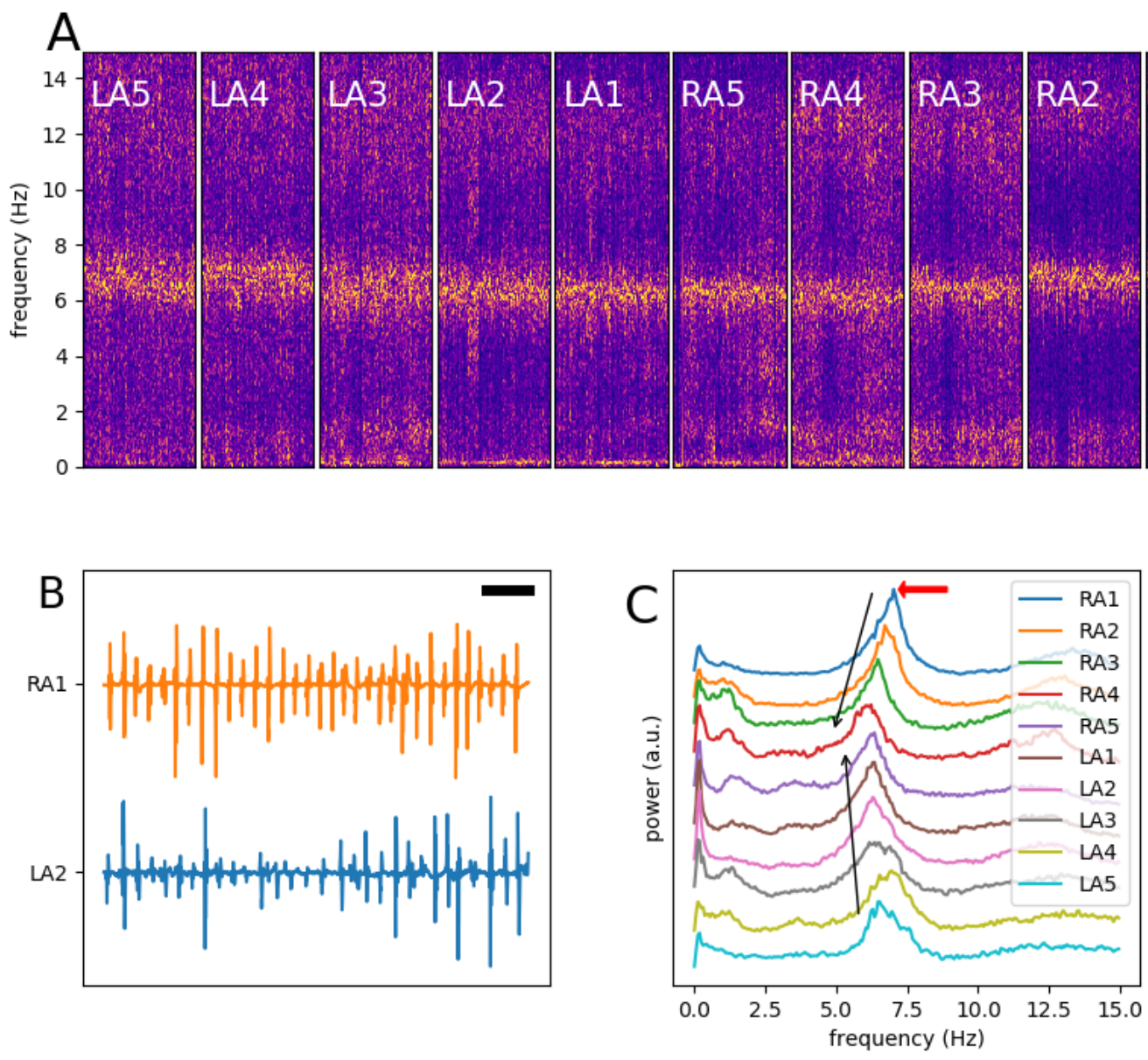
bioRxiv preprint doi: https://doi.org/10.1101/285031; this version posted March 19,2018 . The copyright holder for this preprint (which was not certified by peer review) is the author/funder, who has granted bioRxiv a license to display the preprint in perpetuity. It is made available under aCC-BY-NC 4.0 International license.

Iravanian, Langberg. Frequency Domain Patterns in Atrial Fibrillation.

Figure 4

A
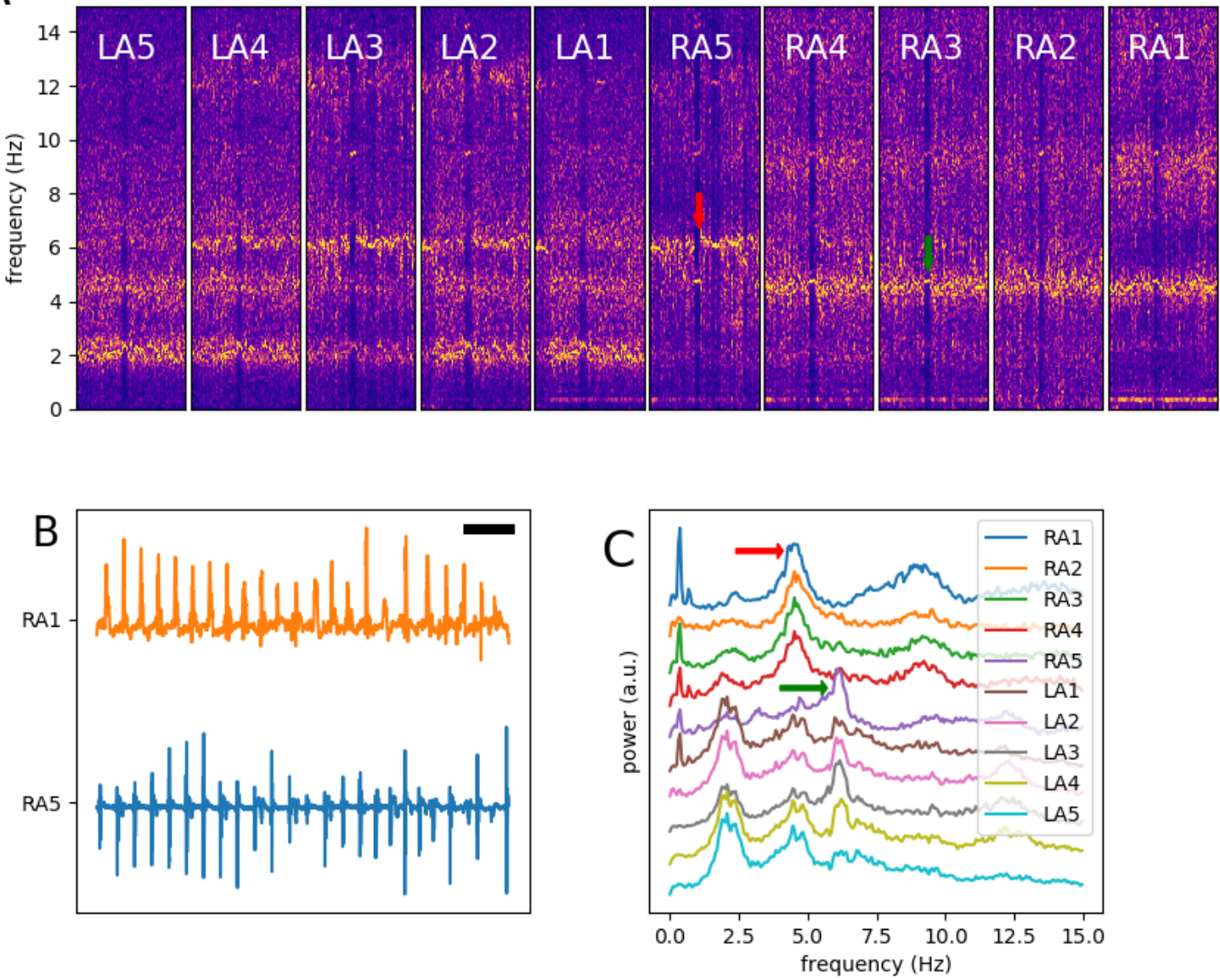
bioRxiv preprint doi: https://doi.org/10.1101/285031; this version posted March 19,2018 . The copyright holder for this preprint (which was not certified by peer review) is the author/funder, who has granted bioRxiv a license to display the preprint in perpetuity. It is made available under aCC-BY-NC 4.0 International license.

Iravanian, Langberg. Frequency Domain Patterns in Atrial Fibrillation.

Figure 5
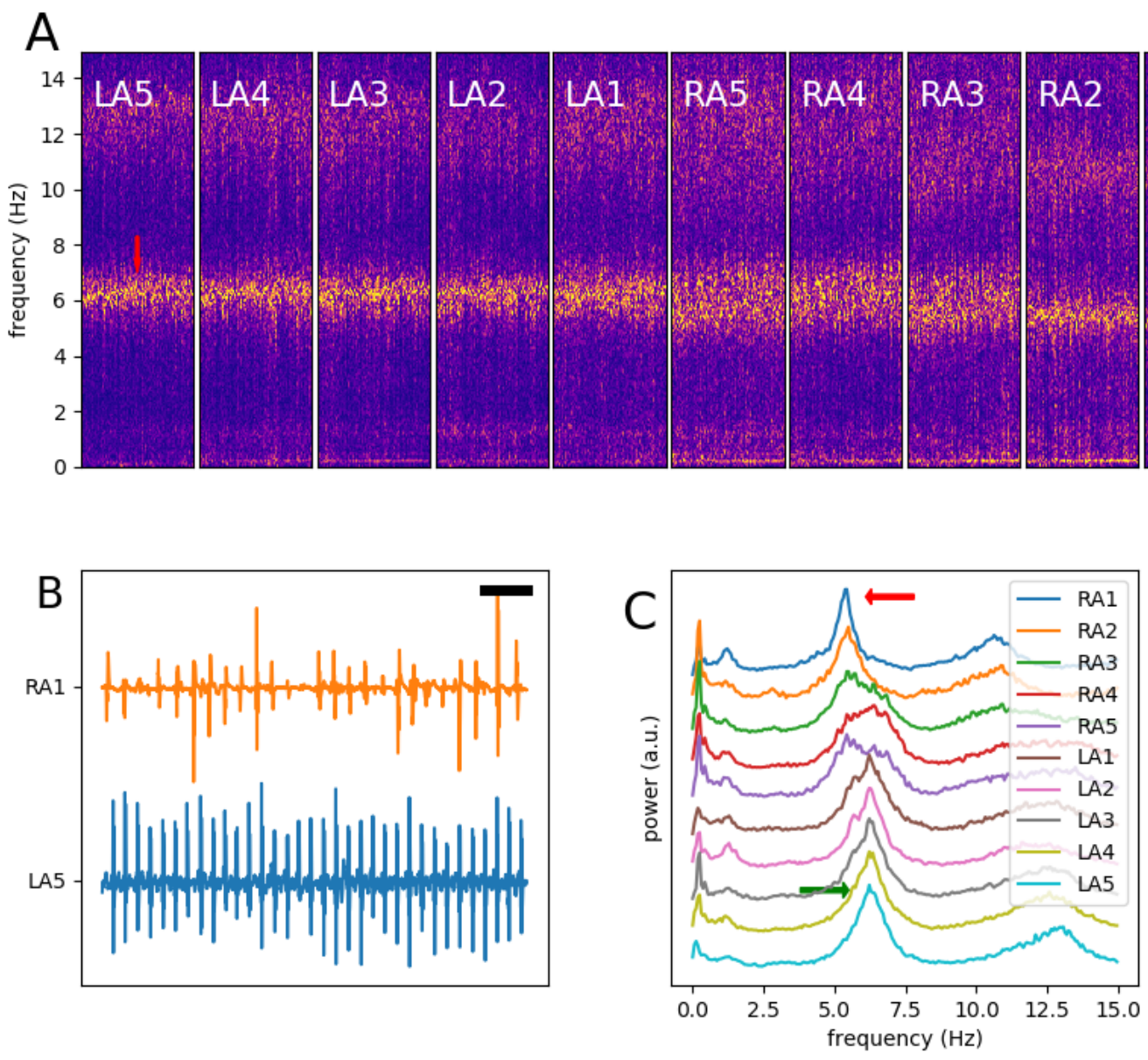
bioRxiv preprint doi: https://doi.org/10.1101/285031; this version posted March 19,2018 . The copyright holder for this preprint (which was not certified by peer review) is the author/funder, who has granted bioRxiv a license to display the preprint in perpetuity. It is made available under aCC-BY-NC 4.0 International license.

Iravanian, Langberg. Frequency Domain Patterns in Atrial Fibrillation.

Figure 6
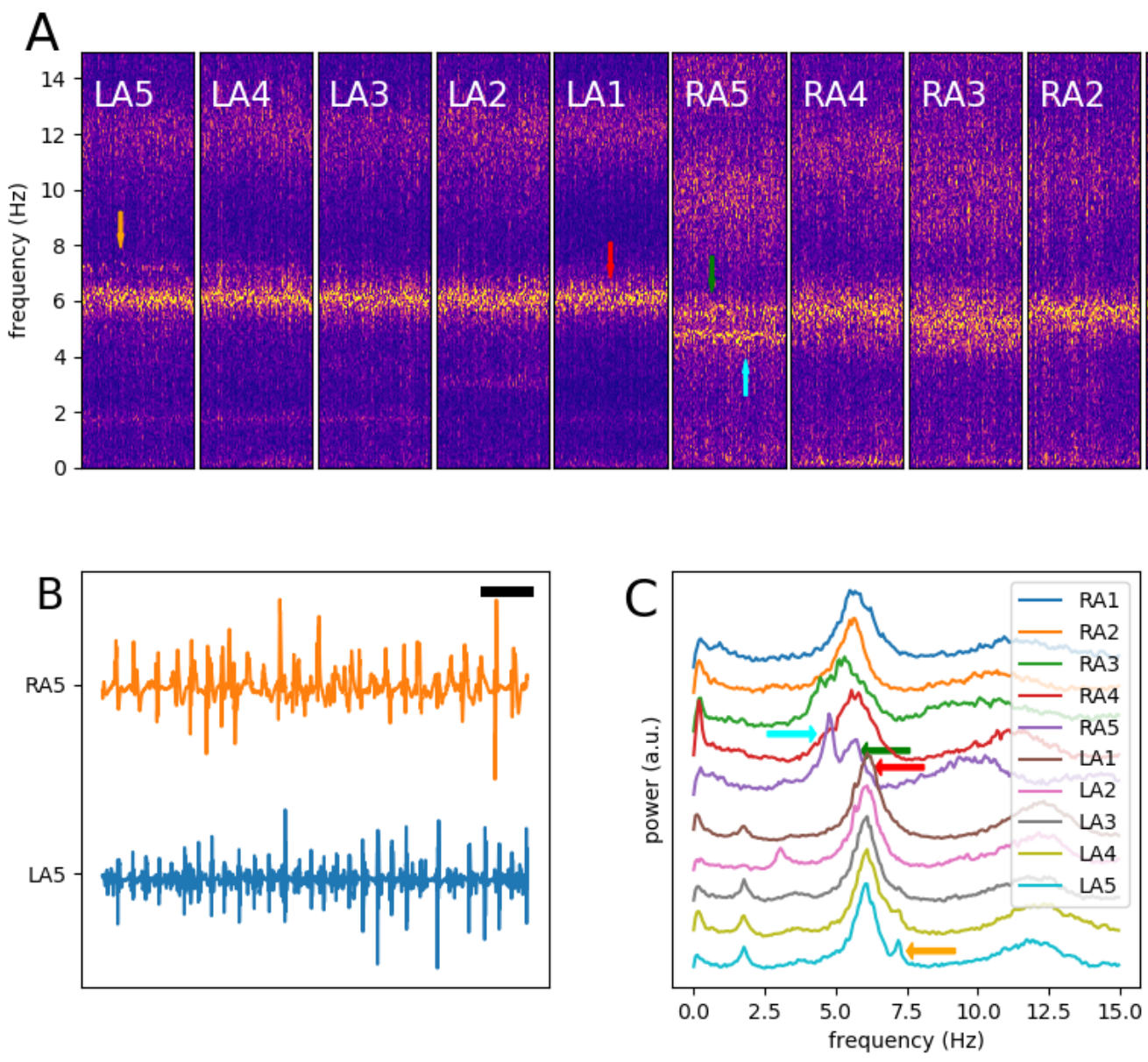
bioRxiv preprint doi: https://doi.org/10.1101/285031; this version posted March 19,2018. The copyright holder for this preprint (which was not certified by peer review) is the author/funder, who has granted bioRxiv a license to display the preprint in perpetuity. It is made available under aCC-BY-NC 4.0 International license.

Iravanian, Langberg. Frequency Domain Patterns in Atrial Fibrillation.

Figure 7
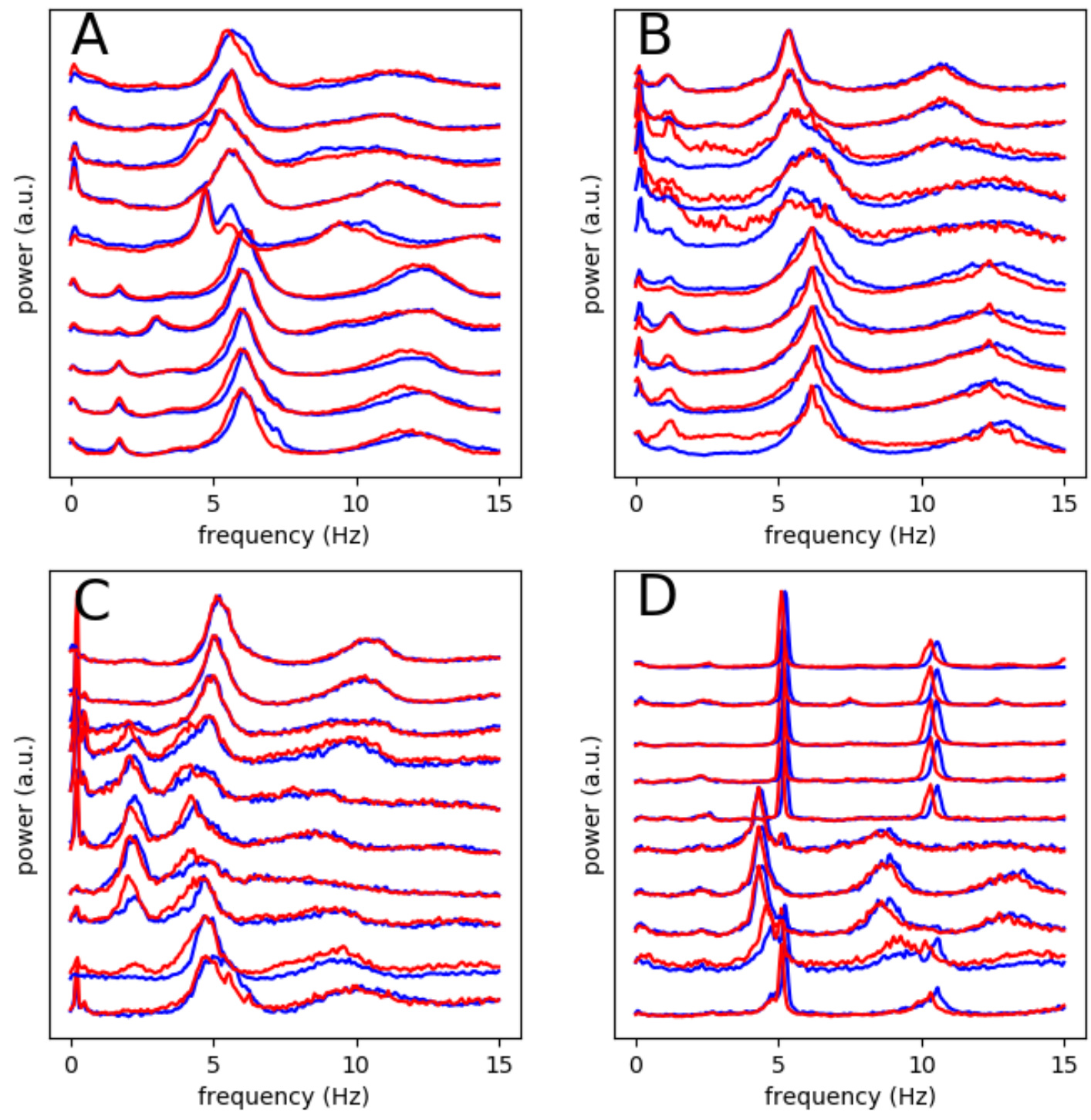
bioRxiv preprint doi: https://doi.org/10.1101/285031; this version posted March 19, 2018. The copyright holder for this preprint (which was not certified by peer review) is the author/funder, who has granted bioRxiv a license to display the preprint in perpetuity. It is made available under aCC-BY-NC 4.0 International license.

\section{Figure 8}
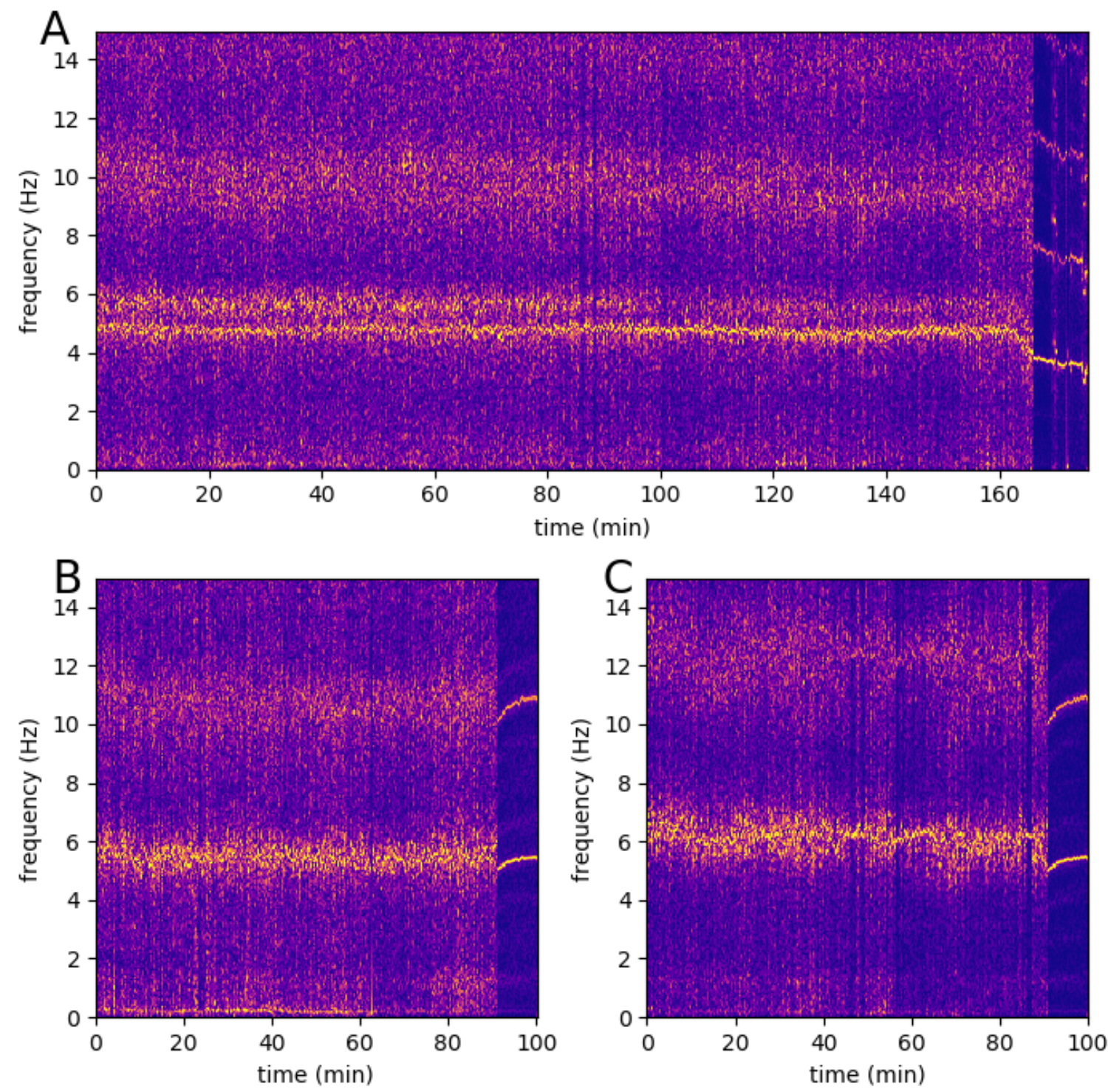